\title{
SEMINAR PEMBERIAN CODMAN PENDULAR EXERCISE DAN MULLIGAN MOBILIZATION TERHADAP PENINGKATAN LINGKUP GERAK SENDI PENDERITA FROZEN SHOULDER DI RUMAH SAKIT GRANDMED LUBUK PAKAM
}

\author{
Siti Sarah Bintang ${ }^{1 *}$, Sabirin Berampu ${ }^{2}$, Mawaddah Saleha ${ }^{3}$, Miftahul Zannah $^{1,}$ \\ Simson Sinuhaji ${ }^{1}$, Leni Sumiati Silaban ${ }^{1}$
${ }^{1}$ Program Studi Fisioterapi Program Sarjana, Institut Kesehatan Medistra Lubuk Pakam
${ }^{2}$ Program Studi Pendidikan Profesi Fisioterapis Program Profesi, Institut Kesehatan Medistra Lubuk Pakam
${ }^{3}$ Program Studi Profesi Ners, Institut Kesehatan Medistra Lubuk Pakam

\author{
JIn. Sudirman No.38 Lubuk Pakam, Kabupaten Deli Serdang, \\ Sumatera Utara - Indonesia \\ *email korespondensi author:sitisarahbintang228@gmail.com
}

DOI $10.35451 / j p k . v 1 \mathrm{i} 1.759$

\begin{abstract}
Abstrak
Capsulitis adhesive atau nama lain Frozen shoulder adalah kaku atau beku pada bahu yang mengakibatkan nyeri bahu yang menetap lebih dari 3 bulan kondisi inflamasi ini menebabkan fibrosis kapsul sendi glenohumeral dan disertai kekakuan progresif secara bertahapdan keterbatasan lingkup gerak sendi seperti gerakan ekternal rotasi. Range of motion (ROM) adalah batas atau besarnya suatu gerakan pada sendi secara normal. ROM juga digunakan sebagai salah satu tolak ukur ada atau tidaknya gangguan/kelainan pada regio sendi tertentu Codman pendular exercises merupakan latihan yang dkelan dengan latihan codman. Latihan ini digunakan untuk memobilisasi sendi glenohumeral secara pasif. Mulligan mobilization with movement adalah terapi manual dengan posisi menahan beban yang memanfaatkan aktifitas aktif yang dilakukan oleh pasien. Kegiatan pengabdian ini dilakukan melalui seminar menggunakan metode ceramah, tanya jawab dan demonstrasi. Sampel yang diambil adalah penderita frozen shoulder dengan jumlah 14 orang. Hasil uji statistic diperoleh p-value a 0,05 maka dapat disimpulkan hipotesa pada penelitian di terima yaitu : "Adanya Pengaruh Pemberian Codman Pendular Exercises Dan Mulligan Mobilization With Movement Terhadap Peningkatan Range Of Motion Pada Penderita Frozen Shoulder"
\end{abstract}

Kata Kunci: Frozen Shoulder, Codman pendular exercises, Range Of Motion

\begin{abstract}
Adhesive capsulitis or frozen shoulder is a stiff or frozen shoulder that causes shoulder pain that persists for more than 3 months. This inflammatory condition causes fibrosis of the glenohumeral joint capsule and is accompanied by gradual progressive stiffness and limited range of motion of the joint such as external rotational movement. Range of motion (ROM) is the limit or magnitude of a normal joint movement. ROM is also used as a benchmark for the presence or absence of disorders/abnormalities in certain joint regions. Codman pendular exercises are exercises that are coordinated with Codman exercises. This exercise is used to passively mobilize the glenohumeral joint. Mulligan mobilization with movement is a manual therapy with a weight-bearing position that utilizes the active activities carried out by the patient. This service activity is carried out through seminars using lecture, question and answer methods and demonstrations. The samples taken were patients with frozen shoulder with a
\end{abstract}


Received: 17 June 2021 :: Accepted: 23 June 2021 :: Published: 30 June 2021

total of 14 people. The results of the statistical test obtained $p$-value $<0.05$, it can be concluded that the hypothesis in the study was accepted, namely: "There is an Effect of Giving Codman Pendular Exercises and Mulligan Mobilization With Movement on Increasing Range Of Motion in Frozen Shoulder Patients"

Keywords: Frozen Shoulder, Codman pendular exercises, Range Of Motion

\section{Pendahuluan}

Prevalensi frozen shoulder pada wanita mencapai $59-70 \%$. Data lain menunjukkan bahwa pada wanita terjadi 3,38 dan pada laki-laki 2,36 dari 1000 orang pertahun atau 2,4 orang per 1000 orang untuk kedua jenis kelamin terutama usia paruh baya. Onset usia yang mengalami adalah usia 50 tahun. Ada riwayat penyakit keluarga sebesar 9,5\% (Cohen, 2015).

Capsulitis adhesive atau nama lain Frozen shoulder adalah kaku atau beku pada bahu yang mengakibatkan nyeri bahu yang menetap lebih dari 3 bulan kondisi inflamasi ini menebabkan fibrosis kapsul sendi glenohumeral dan disertai kekakuan progresif secara bertahapdan keterbatasan lingkup gerak sendi seperti gerakan ekternal rotasi (Mezian, 2018).

Terjadi hyperplasia dengan peningkatan vaskularisasi selama periode awal, yang kemudian menyebabkan fibrosis di subsynovium dan sinovium jaringan kapsul. Ini kondisi dimulai sebagai respons imun, yang berlanjut dengan sinovitis inflamasi dan fbrosis kapsuler (Tamai, 2014).

Terjadinya frozen shoulder dikaitkan dengan diabetes mellitus, disfungsi tiroid, kontraktur dupuytren, penyakit autoimun, dan pengobatan kanker payudara. Pengobatan umum dan manajemen dari kondisi ini melibatkan penggunaan obat antiinflamasi nonsteroid, suntikan kortikosteroid ke dalam darah (Neviaser, 2010).

Manifestasi yang terjadi pada penderita frozen shoulder antara lain peradangan dan perubahan pada kapsul atau bursa antara scapula dan humerus. Secara patologis prosesnya dibagi menjadi 4 tahap. Tahap pertama pasien merasakan nyeri yang progresif di daerah deltoid yang mana nyerinya timbul pada malam hari. Ada keterbatasan gerak tetapi menghilang ketika disuntikkan anestesi ke dalam sendi. Dalam sendi terdapat ada tanda tanda sinovitis tanpa perlengketan atau kontraktur. Pada tahap kedua terjadinya kekakuan sendi, pada tahap ketiga terjadi kehilangan gerakan yang normal atau keterbatasan Range of motion dan setiap gerakan timbul nyeri atau rasa sakit (Yuan, 2017).

Range of motion (ROM) adalah batas atau besarnya suatu gerakan pada sendi secara normal. ROM juga digunakan sebagai salah satu tolak ukur ada atau tidaknya gangguan/kelainan pada regio sendi tertentu. ROM juga disebut rentang gerak, yang merupakan pergerakan sendi pada berbagai bidang seperti sagital, transversal, dan frontal (Potter, 2010).

Adapun intervensi fisioterapi yang digunakan untuk penanganan kasus frozen shoulder untuk peningkatan ROM pada kasus frozen shoulder adalah dengan pemberian teknik Codman pendular exercises dan Mulligan mobilization with movement (MWM).

Mulligan mobilization with movement adalah terapi manual dengan posisi menahan beban yang memanfaatkan aktifitas aktif yang dilakukan oleh pasien. MWM memiliki konsep yang mengadopsi parameter yang berurutan seperti posisi, tekhnik, alat yang diperlukan, waktu dan set (Dowell, 2014).

Codman pendular exercises merupakan latihan yang dkelan dengan latihan codman. Latihn ini digunakan untuk memobilisasi sendi glenohumeral secara pasif. Latihan inin melibatkan pasien untuk melakukan gerakan seperti menggerakkan tangan atau lengan tanpa berkontraksi. Tekhnik gerakan 
Received: 17 June 2021 :: Accepted: 23 June 2021 :: Published: 30 June 2021

pada latihan ini adalah mediolateral, anteroposterior, dan gerakan sirkuler. Gerakan ini diberikan selama 10 sampai 15 detik setiap pengulangan (Cunningham, 2020).

Latihan Codman pendular pernah dilakukan oleh Latif pada skripsinya tahun 2015 tentang penambahan Codman pendular exercises kepada pasien frozen shoulder dan memberikan hasil Range of Motion (ROM) sendi glenohumeral yang meningkat dan tekhnik Mulligan mobilization with movement merupakan suatu teknik mobilisasi yang dikembangkan oleh Mulligan pada tahun 1993. Teknik ini sudah di di teliti kembali oleh Hafiz, dkk, tahun 2015, dan hasil dari penelitiannya ampuh untuk meningkatkan ROM pada penderia frozen shoulder (Latif, 2015).

Seminar ini bertujuan untuk mensosialisasikan dan memberikan edukasi kepada masyarakat agar dapat memanfaatkan latihan codman pendular terhadap lingkup gerak sendi pada penderita frozen shoulder.

\section{Metode}

Kegiatan pengabdian ini dilakukan melalui seminar menggunakan metode ceramah, tanya jawab dan demonstrasi. Sampel yang diambil adalah penderita frozen shoulder dengan jumlah 14 orang. Seminar dilakukan untuk melihat pengaruh Codman Pendular Exercise Terhadap Peningkatan Lingkup Gerak Sendi Penderita Frozen Shoulder.

\section{Hasil dan Pembahasan Hasil}

Berdasarkan hasil seminar karakteristik responden berdasarkan umur 45-50 tahun adalah sebanyak 4 orang $(28,6 \%)$, umur $51-55$ sebanyak 6 orang $(42,9 \%)$, sedangkan jumlah responden berdasarkan umur 56-60 sebanyak 4 orang $(28,6 \%)$.

Jumlah responden berdasarkan jenis kelamin perempuan adalah sebanyak 9 orang $(64,3 \%)$ sedangkan jumlah responden laki-laki adalah sebanyak 5 orang $(35,7 \%)$.
Tabel 1. Sebelum Pemberian Codman Pendular Exercises Dan Mulligan

Mobilization With Movement

Sebelum Pemberian Codman Pendular Exercises Dan Mulligan Mobilization With

\begin{tabular}{lcccc}
\multicolumn{5}{c}{ Movement } \\
\hline $\begin{array}{c}\text { Nilai } \\
\text { Minimu } \\
\mathrm{m}\end{array}$ & $\begin{array}{c}\text { Nilai } \\
\text { Maximu } \\
\mathrm{m}\end{array}$ & Mean & $\begin{array}{c}\text { Std } \\
\text { Devia } \\
\text { si }\end{array}$ \\
\hline $\begin{array}{l}\text { Fleksi } \\
\text { Ekste }\end{array}$ & 80 & 95 & 86,00 & 3,961 \\
nsi & 20 & 36 & 26,79 & 4,061 \\
$\begin{array}{l}\text { Abdu } \\
\text { ksi }\end{array}$ & 79 & 98 & 90,36 & 5,611 \\
$\begin{array}{l}\text { Inter } \\
\text { nal }\end{array}$ & 35 & 58 & 45,00 & 6,668 \\
$\begin{array}{l}\text { Rotas } \\
\text { i }\end{array}$ & & & & \\
$\begin{array}{l}\text { Ekste } \\
\text { rnal }\end{array}$ & 30 & 45 & 36,29 & 3,970 \\
Rotas & & & & \\
i & & & & \\
\hline
\end{tabular}

Jumlah responden berdasarkan pekerjaan pada adalah IRT sebanyak 8 orang $(57,1 \%)$, K.Swasta sebanyak 1 orang $(7,1 \%)$, Petani sebanyak 2 orang $(14,3 \%)$, PNS sebanyak 1 orang $(7,1 \%)$, Tukang sebanyak 2 orang $(14,3 \%)$.

Berdasarkan tabel 1 rerata ROM di atas sebelum penanganan adalah Fleksi 86,00 (terbatas), Ekstensi 26,79 (terbatas), Abduksi 90,36 (terbatas), Endorotasi 45,00 (terbatas), Eksorotasi 36,29 (terbatas).

Tabel 2. Sesudah Pemberian Codman

Pendular Exercises Dan Mulligan

Mobilization With Movement

Sesudah Pemberian Codman Pendular Exercises Dan Mulligan Mobilization With

\begin{tabular}{|c|c|c|c|c|}
\hline \multicolumn{5}{|c|}{ Movement } \\
\hline & $\begin{array}{c}\text { Nilai } \\
\text { Minimu } \\
\text { m }\end{array}$ & $\begin{array}{c}\text { Nilai } \\
\text { Maximu } \\
\mathrm{m}\end{array}$ & $\begin{array}{c}\text { Mea } \\
\mathrm{n}\end{array}$ & $\begin{array}{l}\text { Std } \\
\text { Deviati } \\
\text { on }\end{array}$ \\
\hline Fleksi & 83 & 97 & $\begin{array}{c}88,0 \\
0\end{array}$ & 4,336 \\
\hline $\begin{array}{l}\text { Ekstens } \\
\mathrm{i}\end{array}$ & 24 & 38 & $\begin{array}{c}29,6 \\
4\end{array}$ & 4,199 \\
\hline Abduksi & 83 & 102 & $\begin{array}{c}93,5 \\
0\end{array}$ & 5,317 \\
\hline $\begin{array}{l}\text { Internal } \\
\text { Rotasi }\end{array}$ & 39 & 59 & $\begin{array}{c}48,3 \\
6\end{array}$ & 6,008 \\
\hline $\begin{array}{l}\text { Ekstern } \\
\text { al } \\
\text { Rotasi }\end{array}$ & 33 & 48 & $\begin{array}{c}39,4 \\
3\end{array}$ & 4,237 \\
\hline
\end{tabular}

Berdasarkan pengumpulan data yang dilakukan di Poli Fisioterapi Rumah Sakit Grandmed Lubuk Pakam tentang Frozen Shoulder, maka hasil pengolahan data rerata sesudah pemberian pada seminar ini dapat dilihat pada tabel 2 diatas ini. 
Received: 17 June 2021 :: Accepted: 23 June 2021 :: Published: 30 June 2021

Hasil uji statistic diperoleh p-value a $<$ 0,05 maka dapat disimpulkan hipotesa pada penelitian di terima yaitu : "Adanya Pengaruh Pemberian Codman Pendular Exercises Dan Mulligan Mobilization With Movement Terhadap Peningkatan Range Of Motion Pada Penderita Frozen Shoulder"

Tabel 3. Rerata sebelum dan sesudah

\begin{tabular}{lccccc}
\hline $\begin{array}{l}\text { Interv } \\
\text { ensi }\end{array}$ & Mean & $\begin{array}{c}\text { Lowe } \\
\mathbf{r}\end{array}$ & $\begin{array}{c}\text { Uppe } \\
\mathbf{r}\end{array}$ & $\begin{array}{c}\text { Std. } \\
\text { Deviasi }\end{array}$ & $\begin{array}{c}\text { P } \\
\text { Value }\end{array}$ \\
\hline $\begin{array}{l}\text { Sebelu } \\
\mathrm{m} \text { dan }\end{array}$ & & & & & \\
$\begin{array}{l}\text { Sesuda } \\
\mathrm{h}\end{array}$ & & & & & \\
Fleksi & -2.786 & - & - & 1.122 & 0.000 \\
& & 3.433 & 2.138 & & \\
Eksten & -2.857 & - & - & 1.027 & 0.000 \\
si & & 3.450 & 2.264 & & \\
Abduk & -3.143 & - & - & .770 & 0.000 \\
si & & 3.588 & 2.698 & & \\
Endoro & -3.357 & - & - & 1.082 & 0.000 \\
tasi & & 3.982 & 2.733 & & \\
Eksoro & -3.143 & - & - & 1.231 & 0.000 \\
tasi & & 3.854 & 2.432 & & \\
& & & & & \\
\hline
\end{tabular}

\section{Pembahasan}

Codman Pendular Exercises dan Mulligan Mobilization With Movement dapat menimbukan efek relaksasi otototot sehingga menyebabkan terjadinya penurunan rasa sakit atau nyeri dan mempercepat proses pelepasan perlengketan kapsul sendi pada bahu, mengembalikan dan menjaga ruang lingkup gerak sendi glenohumeral dan dapat membantu mengembalikan fungsi kerja otot pada kaput humerus yang benar (Kisner, dkk, 2014).

Gerakan dari latihan tersebut mampu memberikan gerakan mobilisasi dengan gerakan aktif dari pasien akan memulihkan mobilitas dan fungsi shoulder dengan menghilangkan nyeri yang akan memberikan rileksasis sehingga keterbatasan ROM yang terjadi pada sendi bahu (glenonohumeral, sternoclavicular, acromeoclavicular, scapulothoracal) berkurang, asumsi ini didukung dengan hasil penelitian Salim dengan judul "Penambahan Teknik Manual Therapy Pada Latihan Pendular Codman Lebih Meningkatkan Lingkup Gerak Sendi Pada Sendi Glenohumeral Penderita Frozen Shoulder".
Pada penelitian ini jumlah responden penelitian adalah sebanyak 14 orang yang menderita frozen shoulder yang datang ke unit Poli Fisioterapi Rumah Sakit Grandmed Lubuk Pakam dari bulan Maret 2019. Berdasarkan umur yang terlibat 45-50 4 orang $(28,6 \%), 51-556$ orang $(42,9 \%), 56-604$ orang $(28,6 \%)$. Jumlah perempuan yang terlibat 9 $(64,3 \%)$ orang dan 5 orang laki-laki $(35,7 \%)$. Pekerjaan IRT 8 orang $(57,1 \%)$, K.Swasta 1 orang $(7,1 \%)$, Petani $2(14,3 \%)$, PNS 1 orang $(7,1 \%)$, Tukang 2 orang(14,3 \%). Kondisi ini hampir sama dengan yang dilaporkan oleh beberapa peneliti bahwa frozen shoulder kebanyakan terjadi pada usia 40-65 dan lebih banyak mengenai wanita. Kebanyakan terjadi pada usia 40-65 tahun, berhubungan dengan proses penuaan, ditanbah lagi dengan pekerjaan ibu rumah tangga yang tidak terkontrol dan rentan terkena cidera. Pada tahap ini penurunan sistem tubuh berlanjut, khususnya penurunan level hormon antara lain level hormon Dehydroepiandrosterone, testosteron, growth hormene dan estrogen (Salim, 2014).

Penderita frozen shoulder lebih banyak mengenai wanita karena wanita pada usia 45-65 tahun lebih banyak mengalami perubahan hormon, pre menopause dan post menopause yang merupakan salah satu pencetus frozen shoulder (Tamai, 2014).

\section{Kesimpulan}

Berdasarkan hasil uji statistic dan pembahasan di atas maka dapat disimpulkan bahwa ada Pengaruh Pemberian Codman Pendular Exercises Dan Mulligan Mobilization With Movement Terhadap Peningkatan Range Of Motion Pada Penderita Frozen Shoulder.

\section{Ucapan Terima Kasih}

Penulis menyampaikan terima kasih kepada:

a. Lembaga Penelitian dan Pengabdian Kepada Masyarakat (LPPM) Institut Kesehatan Medistra Lubuk Pakam 
Received: 17 June 2021 :: Accepted: 23 June 2021 :: Published: 30 June 2021

b. Direktur Rumah Sakit Granmed Lubuk Pakam

\section{Daftar Pustaka}

Aaron, Cohen Mohamed Abedallah. Epidemiology of frozen shoulder, 2015.and Performance. Journal Management Research Review, 38(1):2-28.

Cunningham, F.G. (2015) Obstetric Wiliam. Jakarta: EGC

Dzoyem JP, Melong R, Tsamo AT, Tchinda AT, Kapche DG, Ngadjui BT, Mcgaw LC, Eloff JN, 2017. Cytotoxicity, Antimicrobial and Antioxidant Activity of Eight Compounds Isolated from Entada abyssinica (Fabaceae). Bio Med Central Research Notes, 10: 1-6.

Hidayati N, Mansur M, Juhaeti T, 2013. Variasi Serapan Karbondioksida (CO2) Jenis-jenis Pohon di "Ecopark", Cibinong dan Kaitannya dengan Potensi Mitigasi Gas Rumah Kaca. Pusat Penelitian Biologi LIPI. Cibinong.

Judith L. Walls, Glen W. S. Dowell, Difference in degrees: CEO characteristics and firm environmental disclosure, 2014, https://doi.org/10.1002/smj.212 7

Keller PA, Nugraha AS, 2011. Revealing Indigenous Indonesian Traditional Medicine: antiinfective agents. Natural Product Communications, 6 (12): 1953 1966.

Kisner, C dan Colby L. A. 2007. Therapeutic Exercise: Foundations and Techniques. 5th Ed. Philadelphia: F. A. Davis Company. PP: 2

K. Tamai, M. Akutsu, and Y. Yano, "Primary frozen shoulder: brief review of pathology and imaging abnormalities," Journal of Orthopaedic Science, vol. 19, no. 1, pp. 1-5, 2014

Neviaser AS and Hannafin JA (2010) Adhesive capsulitis: A review of current treatment. The American Journal of Sports Medicine 38: 2346-2356

Solikin, 2009. Potensi jenis-jenis herba liar di Kebun Raya Purwodadi sebagai obat. Di dalam: Setiawan, Rahayu S, Rumhayati B, Alghofari AR, Naba A, Maryanto S, Widodo, (eds) Proceeding Basic Science National Seminar; Malang, February 21st 2009, Malang: Brawijaya University. p VIII-47 52 